\title{
INTEGRATION OF JEDDAH HISTORICAL BIM AND 3D GIS FOR DOCUMENTATION AND RESTORATION OF HISTORICAL MONUMENT
}

\author{
A. Baik ${ }^{\text {a }}$, R. Yaagoubi ${ }^{b}$, J. Boehm $^{\mathrm{c}}$ \\ ${ }^{a}$ Dept. of Geomatic Engineering, University College London, Gower Street, London, WC1E 6BT UK - \\ Ahmad.Baik.12@ucl.ac.uk \\ ${ }^{\mathrm{b}}$ Dept. of Geomatics, King Abdul-Aziz University, Abdullah Sulayman Street, Jeddah, 21589 Saudi Arabia - \\ ryaagoubi@kau.edu.sa \\ ${ }^{c}$ Dept. of Geomatic Engineering, University College London, Gower Street, London, WC1E 6BT UK - \\ j.boehm@ucl.ac.uk
}

\section{KEY WORDS: HISTORIC JEDDAH, HBIM, TERRESTRIAL LASER SCANNING, HERITAGE RECORDING}

\begin{abstract}
:
This work outlines a new approach for the integration of 3D Building Information Modelling and the 3D Geographic Information System (GIS) to provide semantically rich models, and to get the benefits from both systems to help document and analyse cultural heritage sites. Our proposed framework is based on the Jeddah Historical Building Information Modelling process (JHBIM). This JHBIM consists of a Hijazi Architectural Objects Library (HAOL) that supports higher level of details (LoD) while decreasing the time of modelling. The Hijazi Architectural Objects Library has been modelled based on the Islamic historical manuscripts and Hijazi architectural pattern books. Moreover, the HAOL is implemented using BIM software called Autodesk Revit. However, it is known that this BIM environment still has some limitations with the non-standard architectural objects. Hence, we propose to integrate the developed 3D JHBIM with 3D GIS for more advanced analysis. To do so, the JHBIM database is exported and semantically enriched with non-architectural information that is necessary for restoration and preservation of historical monuments. After that, this database is integrated with the 3D Model in the 3D GIS solution. At the end of this paper, we'll illustrate our proposed framework by applying it to a Historical Building called Nasif Historical House in Jeddah. First of all, this building is scanned by the use of a Terrestrial Laser Scanner (TLS) and Close Range Photogrammetry. Then, the 3D JHBIM based on the HOAL is designed on Revit Platform. Finally, this model is integrated to a 3D GIS solution through Autodesk InfraWorks. The shown analysis presented in this research highlights the importance of such integration especially for operational decisions and sharing the historical knowledge about Jeddah Historical City. Furthermore, one of the historical buildings in Old Jeddah, Nasif Historical House, was chosen as a test case for the project.
\end{abstract}

\section{INTRODUCTION}

\subsection{Historical Jeddah and the Nasif Historical House: Background}

Jeddah City has a very long history that dates back to more than 3000 years ago. The Old City of Jeddah contains a lot of historic buildings "around 350", which have been built for more than 350 years ago with special characters that exhibit the very culture of the nation. The City is placed in the west side of Hijaz region, through a coastline on the Red Sea. Jeddah is also the welcoming port to the two holy cities of Islam "Madinah and Makkah". Moreover, this city is considered as the tourism and economic capital of the Kingdom of Saudi Arabia (Telmesani et al., 2009). Furthermore, according to (Al-Fakahani, 2005) "Muslim and Arab writers noted that the name Jeddah is taken from the Arabic word for grandmother, while "Jed" means grandfather in Arabic". This links to traditions in the region to the north east of Jeddah where Eve was buried by her descendants in an area known as the cemetery of Mother Eve (Al-Fakahani, 2005). The city of Jeddah contains a number of historical buildings, such as the Nasif Historical House or 'Bayt Nasif' (the project case study, see Figure 1). Sheikh Omar Afandi Nasif constructed the Nasif Historical House during the latter part of the 19th century. The work commenced in 1872 and the building was completed in 1881 (Saban, n.d.). It consists of four storeys with an architectural design of identical dimensions, giving it a very neat and aesthetic look. It is situated right in the middle of Historical Jeddah, at 'Al-Balad'.
The main reason for the house's reputation is due to the fact that during the time when King Abdul-Aziz entered Jeddah in 1925, he stayed in Nasif house, where he met the most notable people of the Jeddah as the house was supposed to be the most distinguished and appropriate residence for the Sultan. The architectural theme of the house is similar to other historic Jeddah buildings with Rowshans and Mashrabiyahs. Until 1975 the house belonged to the Nasif family. One of the heirs, Sheikh Muhammad, turned Nasif House into a private library that contained more than 16,000 books. Today, Bayt Nasif has been restored and has become a museum and cultural centre (SCTA, 2013).

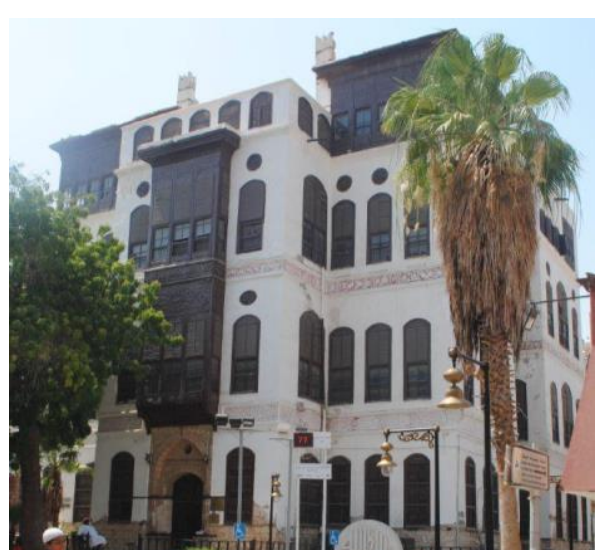

Figure 1: Nasif Historical House 


\subsection{Aims}

In this paper, we aim to integrate 3D Building Information Modelling (BIM) with 3D Geographic Information System (GIS) to provide semantically rich models. Developing such models is very important and useful for the documentation and the preservation of "more than 600 historical buildings". Indeed, this integration allows getting the benefits from BIM and 3D GIS systems to help document and analyse cultural heritage sites. In addition, the proposed framework is based on the Jeddah Historical Building Information Modelling process (JHBIM) (Baik et al., 2013) .

\section{RELATED WORKS}

\subsection{Jeddah Historical Building Information (JHBIM) and Architectural Library (HAOL)}

The Aim of using JHBIM was to provide an interactive solution to move from the zero level of BIM "CAD and 2D drawings" to more advance levels of BIM "level 2 and level 3" (Baik et al., 2014), in case of supporting the preservation, sharing of the information of such historical buildings with experts and societies involved in the decision making process (Eastman et al., 2011; Fussel et al., 2009). Furthermore, (Saygi et al., 2013) states "BIM will provide the possibility to represent all views (3D model, plans, sections, elevations, and details) automatically". Furthermore, according to (Murphy et al., 2009), the purpose of using Historic Building Information Modeling "HBIM" is to offer interactive parametric objects that represent architectural elements, in order to model historical monuments for TLS point cloud for example (Figure 2). These parametric objects represent the components of the building; they are characterized by their descriptive data and their relationships with other components of the building. The Heritage Preservation of Jeddah Historical City may profit from the development of JHBIM because it helps to document the context, knowledge of materials, construction techniques, the building pathologies. In addition, JHBIM supports a wide range of materials and assemblies that are not available from stock libraries of 3D model parts (Baik et al., 2013). Furthermore, JHBIM can offer number of advantages to The Heritage preservation of Historic Jeddah such as, according to (Baik et al., 2013); "offering full study of proposed renovations and changes before final decisions are made, assisting in maintenance efforts, damage detection on building's surfaces, planning for maintenance and repairs, and allowing wider public building experience as models can be viewed with free viewer software from remote locations". Moreover, JHBIM will offer virtual visits for exterior and interior of the historical building, with improving the management performance and better understanding to decision-making procedure of the preservation. Figure 3 illustrates a 3D model of Nasif Historical House based on JHBIM.

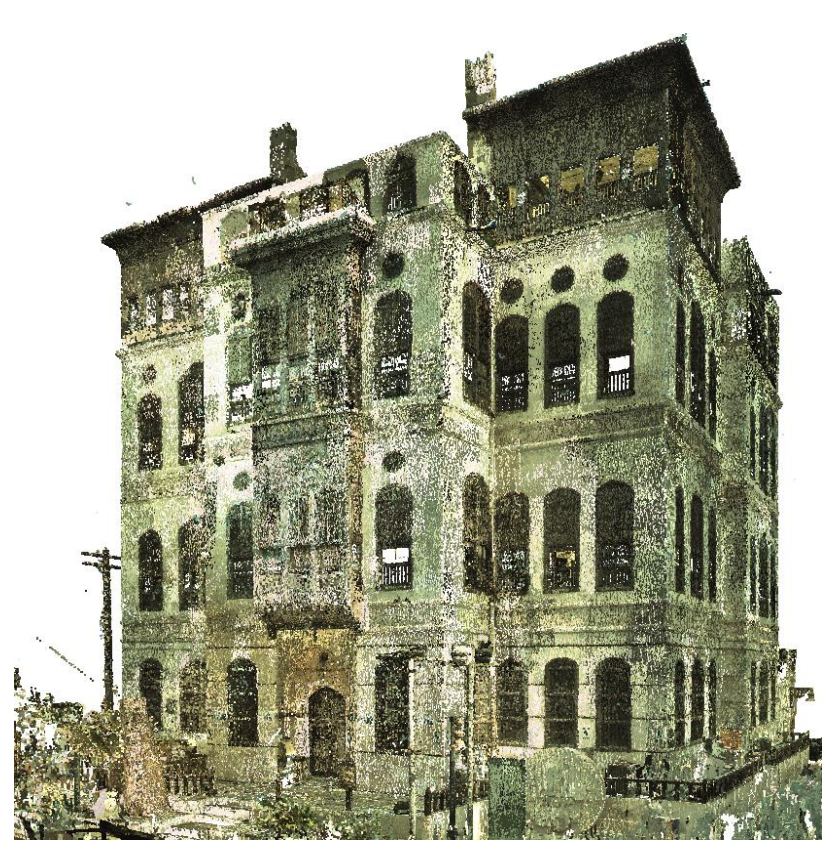

Figure 2: 3D LiDAR point cloud of Nasif Historical House.

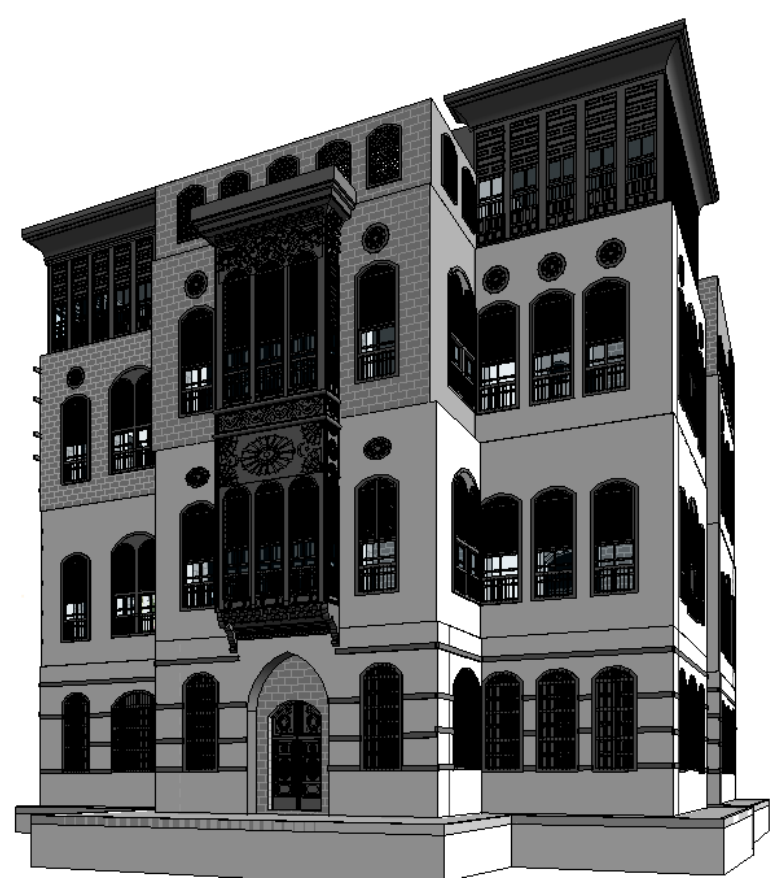

Figure 3: 3D model of Nasif Historical House based on JHBIM.

As such, decision makers in Old Jeddah municipality can be more efficient and effective (Baik et al., 2013). During the process of elaborating the JHBIM, a plug-in called Hijazi Architectural objects library "HAOL" was developed as an extension for existing BIM software platforms such as Autodesk Revit. The "HAOL" was mainly developed from the Hijazi pattern book (Greenlaw, 1995). Figure 4 shows an example of a Hijazi pattern (Manjour). Figure 5 and Figure 6 show its modelling result in the "HAOL" Library. 


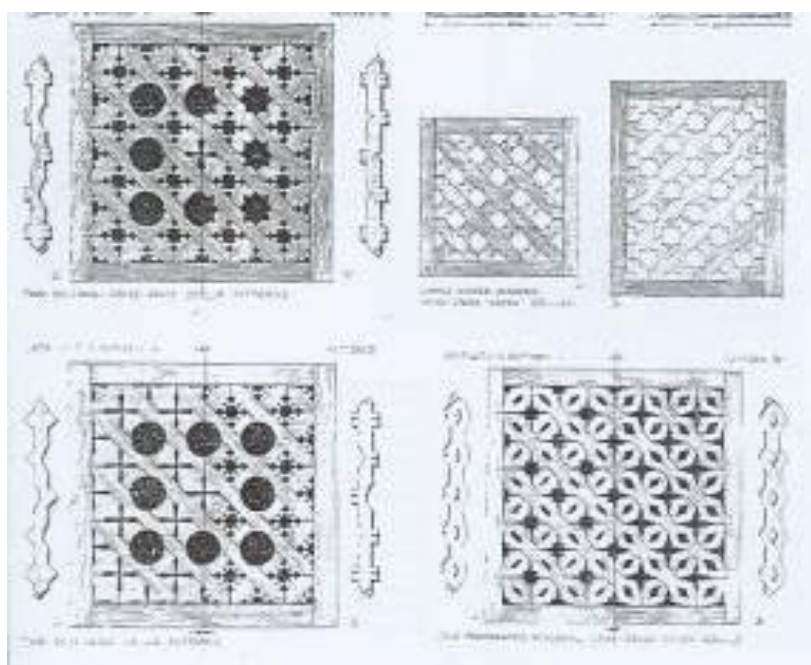

Figure 4: example of the Manjur pattern in old Jeddah (Greenlaw, 1995).

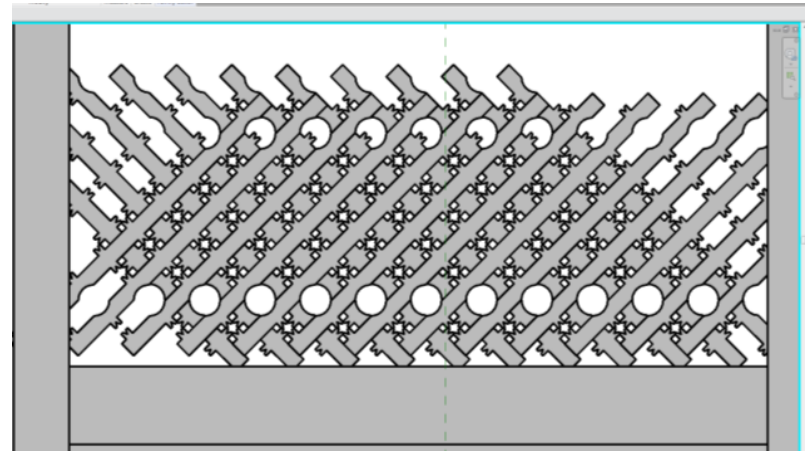

Figure 5: modelling the Manjur pattern in "HAOL" Library

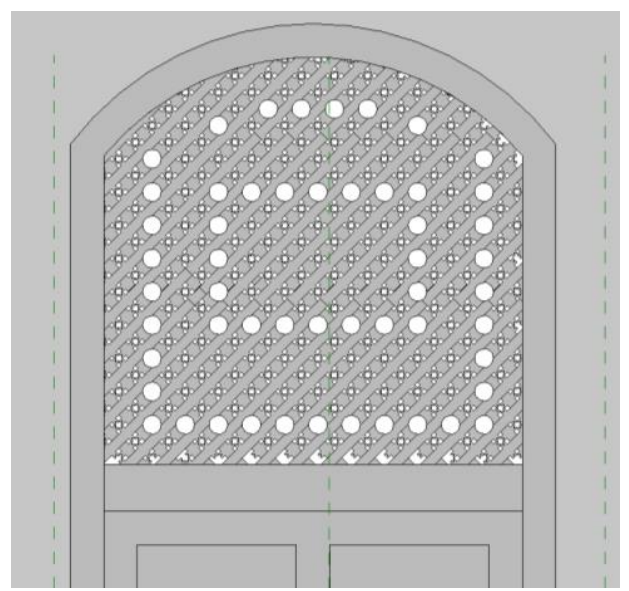

Figure 6: Door with Manjur pattern as Rivet family.

The main purpose of JHBIM was to decrease the modelling time with providing a high level of details (LoD). The modelling process with the Hijazi Architectural objects library "HAOL" was carried out based on LiDAR point cloud data and the Hijazi pattern book. Figure 7 illustrates the process of generating the 3D JHBIM for Nasif Historical House based on Lidar Point Cloud. The resulting model may be used for recreating some of the part, conserving or restoring these unique parts of Historical Buildings. Furthermore, some of Hijazi Objects, such as Roshan and Mashrabiyah, become as main architectural vocabularies of HOAL and can be used to model various Hijazi Historical Buildings. These Architectural vocabularies give the beauty and the unique aspect of such historical buildings.

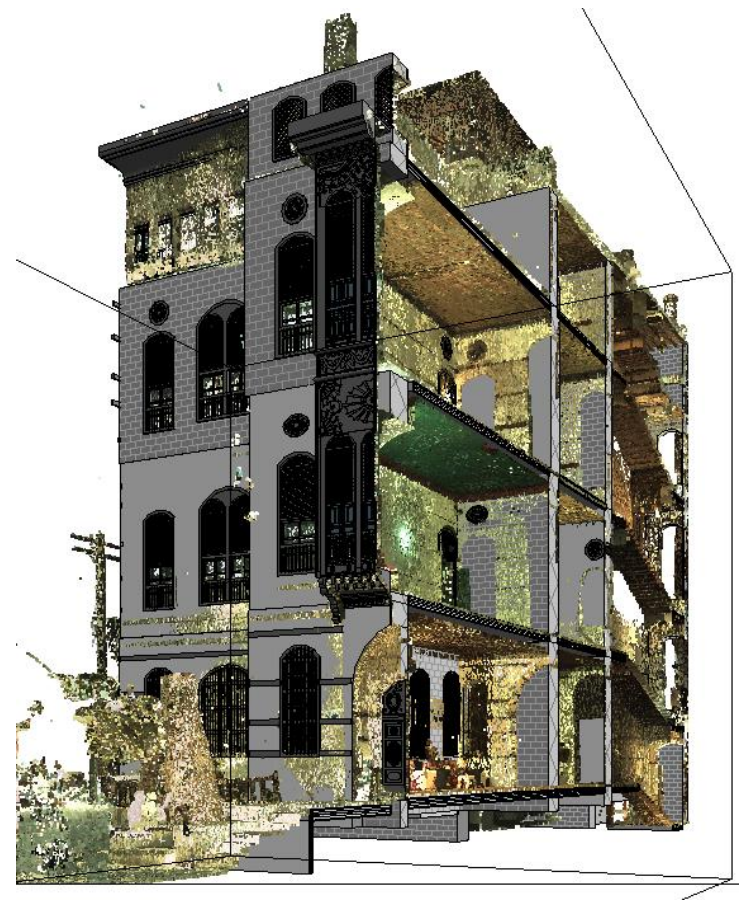

Figure 7: 3D section on the JHBIM model and the point cloud.

\subsection{The Use of 3D GIS in the Preservation of Historical Heritage}

Many recent research works demonstrate the importance of using 3D Geographic Information System (3D GIS) in the field of cultural heritage preservation (Dore and Murphy, 2012; Jayakody et al., 2013; Lorenzini, 2009; Saygi et al., 2013; Wua et al., 2013). A 3D GIS is a system that allows managing, analysing and visualizing $3 \mathrm{D}$ spatial data (taking into consideration their topological relationships) in addition to the thematic properties of objects in the real world (Zlatanova, 1999). The thematic properties of real world objects can be easily and efficiently joined to the geometric representation of 3D spatial data through relational databases. In addition, 3D GIS are characterized by their 'layered' architecture, where each layer contains a subset of features that represent the same theme (Roads, water streams, Buildings, Doors, Windows, Roofs, etc.). According to Wua et al., (2013), 3D GIS platforms are good alternatives to generate convenient and low-cost Historical Building Information Models (HBIM). In fact, these platforms allow saving storage space, efficient retrieval of data and advanced spatial analysis. Another interesting research project was conducted by Dore and Murphy, (2012), where the idea comes from integrating HBIM and 3D GIS. The proposed method consists of two main phases; the first one is to create a 3D model by using HBIM architecture library and the second one is to integrate this $3 \mathrm{D}$ model in a $3 \mathrm{D}$ GIS for more advanced analysis. 


\section{INTGRATATION OF JHBIM AND 3D GIS}

As mentioned earlier, some authors proposed to use 3D GIS with BIM in historical preservation project. However, the cultural and architectural diversity of historical building should be taken into consideration in the integration process between HBIM and GIS. In the case of Hijazi Buildings, the JHBIM has to be semantically enriched in order to take into consideration some important aspect that may be non-architectural. For example, it is necessary to offer information about: 1) the material used in the composition of the building's parts, 2) the historical context of building, 3) the history of reparations that took place in the building, etc.

The concept of the integration between 3D Building Information Modelling and the 3D Geographic Information System (GIS) provides semantically rich models, and allows getting benefits from both systems to help document and analyse cultural heritage sites. In fact, BIMs (and JHBIM) offer powerful tools to automate the modelling process thanks to their parametric objects. However, they have a lack of adding new attributes that are non-architectural (Saygi et al., 2013). In contrast, 3D GIS have great potential to easily integrate new information, in addition to analysing and querying spatial and attribute data. Also, dealing with a large number of historical building information needs high capacity and flexibility in updating database (with reports, images, etc.), which can be an issue in the BIM environment. The major drawback of 3D GIS is their limited functionalities regarding and 3D editing (Saygi et al., 2013). 3D GIS can create and deal perfectly with the simple 3D geometric elements; however, creating complex 3D models with 3D GIS is still an issue. By the integration between HBIM and the GIS, this issue can be solved.

In our case study "Nasif Historical House", we built the BIM model in Autodesk Revit 2015 based on laser scanning point cloud, close range imagery and HOAL library (Figure 7). The Jeddah Historical BIM model contains most of the visual data and some of the MEP "Mechanical, electrical, and plumbing". After creating the JHBIM model, the next step is to integrate the 3D BIM model with 3D GIS for serval purposes such as documentation, restoration and any future management and analysis. It is possible to proceed to such integration for example via FME (Dore and Murphy, 2012) and IFC (Kolbe et al., 2008). However, in our project, we will use both the Revit BIM model (Figure 8) and the GIS data that represent the surrounding environment of "Nasif Historical House" (e.g. road network) (Figure 9) as input for the Autodesk InfraWorks 2015, which is the platform to support this integration. More specifically, the GIS data consist of 1) vector data that represent the road network and footprints for some important landmarks, 2) raster data for the ground imagery and 3) descriptive data to provide relevant information about the history of the building in addition to materials that are used in the building.

According to (Zoog and Schleusner, 2013), importing the data into Autodesk InfraWorks allows architects to present and analyse their designs with relevant surrounding information such as terrain features, transportation networks and other existing building models. As shown in Figure 10, the BIM preserves its high visual quality and level of detail while taking advantage of surrounding data for more advanced analysis. In the case of heritage sites such as Historic Jeddah, the JHBIM/3D GIS integration can be used to provide fully information about the Historic buildings in the area which can be used for documentation, restoration, protection, management, monitoring, visualization, sharing data and any future analysis. Figure 11 illustrates the concept of integration between JHBIM and 3D GIS in Autodesk InfraWorks.

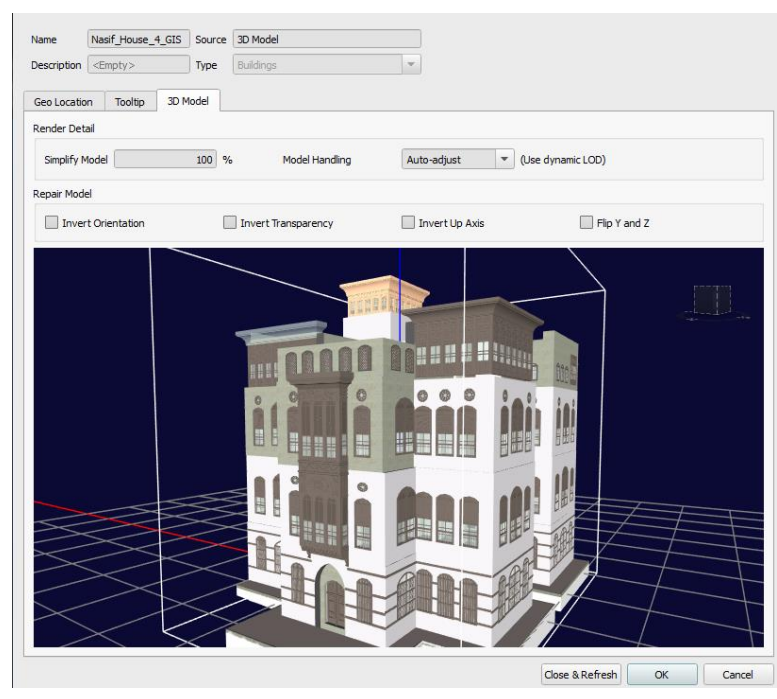

Figure 8: the 3D JHBIM model in Autodesk InfraWorks.

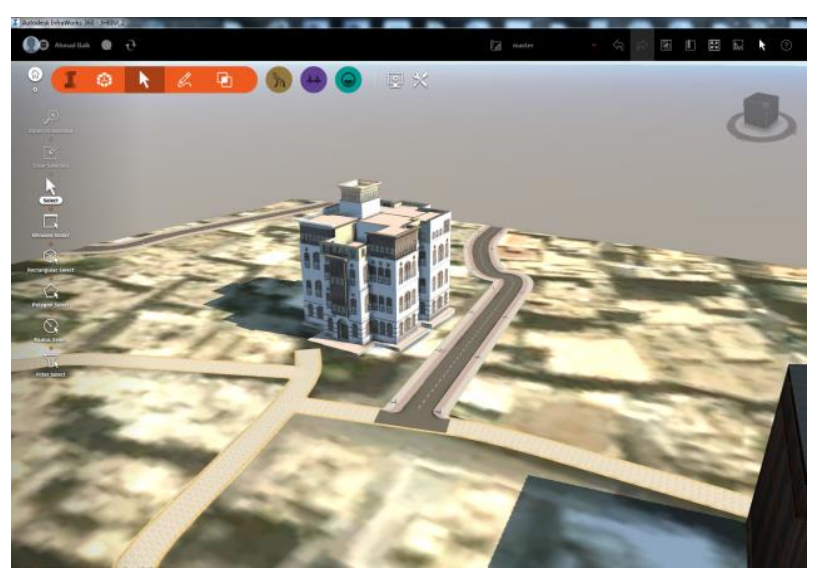

Figure 9: Integrating vector and raster data with the JHBIM of Nasif Historical House within Autodesk InfraWorks.

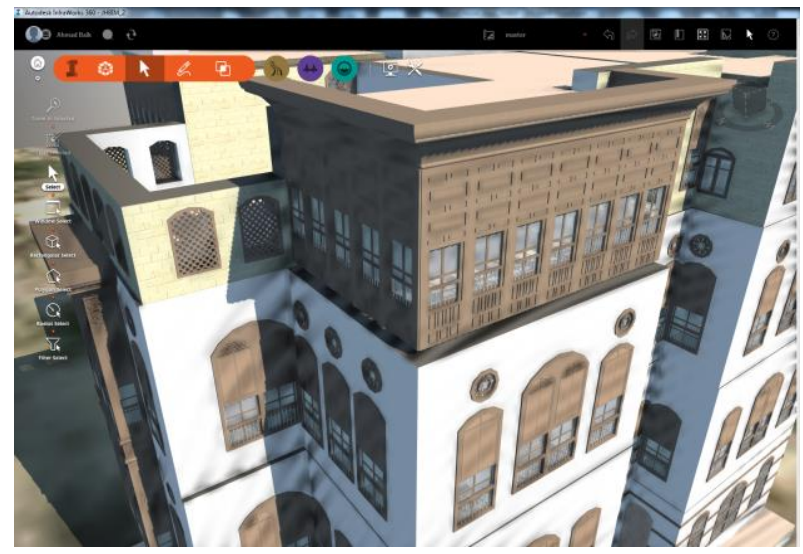

Figure10: the quality of the level of details in Autodesk InfraWorks. 


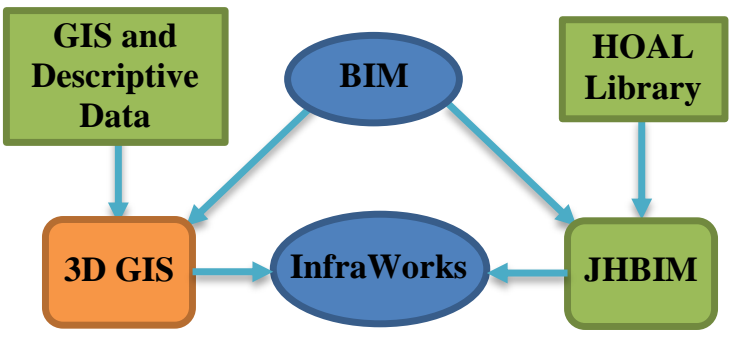

Figure 11: the concept of the integration between JHBIM and 3D GIS in Autodesk InfraWorks.

As we can see in Figure 12, the Autodesk InfraWorks interface allows exploring descriptive attribute data of Nasif Historical House. In addition, it is possible to perform some spatial analysis such as the distance from the building to some centres of interest, as well as analysing the building accessibility from road or pedestrian networks.

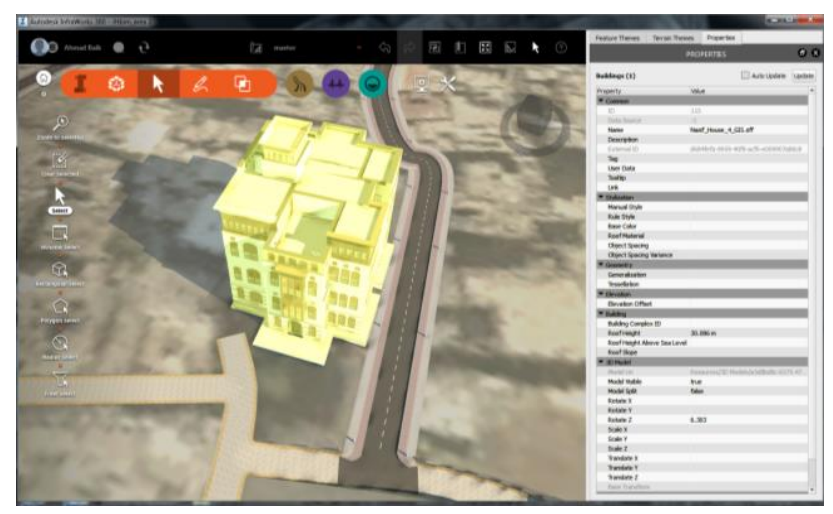

Figure 12: Descriptive attribute data of Nasif Historical House in Autodesk InfraWorks interface.

\section{CONCLUSION}

In this paper, we presented an approach of the integration between JHBIM and 3D GIS via Autodesk InfraWorks platform. We highlighted the importance of such integration for 3D modelling, documentation and information management of historic buildings in Historic Jeddah. We presented a case study of Historical Nasif House, which one of the most important historical monuments in Saudi Arabia. This integration will provide decision-makers with information about the building and the surrounding environment that are relevant for preservation and restoration activities. The process of integration may be divided on three main stages. First of all, modelling the building based on laser scanning survey data and image survey data. Secondly, importing the 3D JHBIM model into Autodesk InfraWorks. And finally, importing the GIS data to enrich the whole model.

The result of this integration can be used for a number of applications, such as documentation, reconstruction and education. In addition, the HBIM/3D GIS integration provide an efficient way for sharing of information and knowledge about architectural heritage for professional users, societies and experts involved in decision making process.

\section{REFERENCES}

Al-Fakahani, H., 2005. Jeddah: The bridge of the red sea: Progress and development, The Arab Publishing House for Encyclopedias. Jeddah, KSA.

Baik, A., Alitany, A., Boehm, J., Robson, S., 2014. Jeddah Historical Building Information Modelling“ JHBIM”-Object Library. ISPRS.

Baik, A., Boehm, J., Robson, S., 2013. Jeddah Historical Building Information Modelling "JHBIM" Old Jeddah -Saudi Arabia.

Dore, C., Murphy, M., 2012. Integration of Historic Building Information Modeling (HBIM) and 3D GIS for recording and managing cultural heritage sites, in: Virtual Systems and Multimedia (VSMM), 2012 18th International Conference on. IEEE, pp. 369-376.

Eastman, C., Teicholz, P., Sacks, R., Liston, K., 2011. BIM handbook: A guide to building information modeling for owners, managers, designers, engineers and contractors. Wiley. com.

Fussel, T., Beazley, S., Aranda-Mena, G., Chevez, A., Crawford, J., Succar, B., Drogemuller, R., Gard, S., Nielsen, D., 2009. National guidelines for digital modelling.

Greenlaw, J., 1995. The coral buildings of Suakin, Islamic Architecture, Planning, Design and Domestic arrengements in a Red Sea port, 2ed ed. Kegan Paul International limited, London, New-York.

Jayakody, A., Rupasinghe, L., Perera, K., Herath, H., Thennakoon, T.M.A., Premanath, S.U., 2013. The Development of the CityGML GeoBIM Extension for Real-Time Assessable Model (Integration of BIM and GIS).

Kolbe, T.H., Gröger, G., Plümer, L., 2008. CityGML-3D city models and their potential for emergency response. Geospatial Inf. Technol. Emerg. Response 257.

Lorenzini, M., 2009. Semantic approach to 3D historical reconstruction, in: Proceedings of the 3rd ISPRS International Workshop 3D-ARCH 2009:“ 3D Virtual Reconstruction and Visualization of Complex Architectures" Trento, Italy, 25-28 February 2009.

Murphy, M., McGovern, E., Pavia, S., 2009. Historic building information modelling (HBIM). Struct. Surv. 27, 311-327. doi:10.1108/02630800910985108

Saban, A., n.d. The Nasif House Jeddah, 1st ed. ed. Printing CO. LTD, Jeddah, Saudi Arabia.

Saygi, gamze, Agugiaro, G., Hamamcıŏ lu - Turan, M., Remondino, F., 2013. Evaluation Of GIS and BIM Roles for the Information Management of Historical Buildings. ISPRS Ann. Photogramm. Remote Sens. Spat. Inf. Sci. Vol. II-5W1 2013 XXIV Int. CIPA Symp. 2 - 6 Sept. 2013 Strasbg. Fr. 283 - 288.

SCTA, 2013. HISTORIC JEDDAH, THE GATE TO MAKKAH. SAUDI COMMISSION FOR TOURISM AND ANTIQUITIES, Saudi Arabia, Jeddah.

Telmesani, A., Sarouji, F., Adas, A., 2009. Old Jeddah A Traditional Arab Muslim City In Saudi Arabia, 1st ed. ed. King Fahad national library, Jeddah. 
The International Archives of the Photogrammetry, Remote Sensing and Spatial Information Sciences, Volume XL-5/W7, 2015 25th International CIPA Symposium 2015, 31 August - 04 September 2015, Taipei, Taiwan

Wua, T.C., Linb, Y.C., Hsuc, M.F., Zhenga, N.W., Chen, W.L., 2013. Improving Traditional Building Repair Construction Quality Using Historic Building Information Modeling Concept. ISPRS-Int. Arch. Photogramm. Remote Sens. Spat. Inf. Sci. 1, 691-694.

Zlatanova, S., 1999. VRML for 3D GIS, in: Proceedings of the 15th Spring Conference on Computer Graphics. Citeseer, p. 1999.

Zoog, C., Schleusner, G., 2013. BIM + GIS = InfraWOW! 